\title{
Nephrotic Syndrome- Steroid Dependent
}

National Cancer Institute

\section{Source}

National Cancer Institute. Nephrotic Syndrome- Steroid Dependent. NCI Thesaurus.

Code C122799.

Nephrotic syndrome characterized by two or more consecutive relapses during steroid tapering or within fourteen days of discontinuing steroids. 